\title{
Comunicació interna post-COVID
}

\author{
Yanna Stefanu' ${ }^{1}$ Marcela Navia ${ }^{2}$ \\ ${ }^{1}$ Antonio Valdivia Consultores \\ ${ }^{2}$ Infocaribe \\ yanna@avconsultores.com \\ contacto@infocaribe.info
}

Recepció: 11/03/2021, acceptació: 04/10/2021

Resum: Aquest treball aprofundeix en els canvis que s'han produït en la comunicació interna en les empreses arran del confinament domiciliari causat per la COVID-19. Les conclusions s'han obtingut gràcies a un estudi realitzat per les autores en el qual han participat empreses grans, mitjanes i petites, així com entitats sense ànim de lucre, amb seu a Espanya o a Colòmbia. L'estudi es va dur a terme durant el primer confinament, el mes d'abril del 2020, amb la finalitat d'aprofundir en els canvis organitzatius i de relació interpersonal en l'àmbit empresarial que s'esperaven arran de la pandèmia. Entre les aportacions dels participants va sorgir de forma espontània la importància de la comunicació interna en les relacions dintre de l'organització i com els directius han de modificar els seus processos de comunicació davant d'aquesta nova situació. Són aquestes les aportacions que es recullen en aquest article.

Paraules clau: comunicació interna, organització empresarial, canvis organitzatius post-COVID.

\section{Comunicación interna post-COVID}

Resumen: Este trabajo profundiza en los cambios que se han implementado en la comunicación interna en las empresas a raíz del confinamiento domiciliario a causa de la COVID-19. Las conclusiones se han obtenido gracias a un estudio realizado por las autoras en el que han participado empresas grandes, medianas y pequeñas, así como entidades sin ánimo de lucro, con sede en España o en Colombia. El estudio se ha realizado durante el primer confinamiento, el mes de abril de 2020, y tuvo como finalidad profundizar en los cambios organizativos y de relación interpersonal en el ámbito empresarial que se esperaban a raíz de la pandemia. Entre las aportaciones de los participantes surgió de forma espontánea la importancia de la comunicación interna en las relaciones dentro de la organización y cómo los directivos debían modificar sus procesos de comunicación ante esta nueva situación. Son estas las aportaciones que se recogen en este artículo.

Palabras clave: comunicación interna, organización empresarial, cambios organizativos post-COVID.

\section{Post-COVID internal communication}


Abstract: This paper delves into the changes that have been implemented in companies' internal communication as a result of lockdown restrictions due to COVID-19. The conclusions were obtained thanks to a study carried out by the authors with participation from large, medium and small companies, as well as non-profit entities, based in Spain or Colombia. The study was carried out during the initial period of lockdown and was intended as an in-depth look at the organisational changes and interpersonal relationships in business environments that were expected as a result of the pandemic. The importance of internal communication in relationships within the organisation arose spontaneously as a factor in participant contributions, as well as how managers should modify their communicative processes in the face of this novel situation. These are the contributions that are included in this article.

Keywords: internal communication, business organisation, Post-COVID organisational changes.

\section{INTRODUCCIÓ}

La comunicació interna en les organitzacions és una eina de gestió que es realitza tant a nivell formal com informal en les tasques quotidianes de les empreses. Fins al mes de març de 2020, quan ens vam veure obligats al confinament per afrontar la pandèmia de la COVID-19, la comunicació interna es resolia, sobretot, mitjançant reunions personals, comunicació a través de correu electrònic o de la intranet de les empreses.

Però va arribar el confinament de manera sobtada, cosa que no va permetre a les organitzacions de poder planificar aquesta nova situació, i no van tenir temps de poder-s'hi adaptar. Tot plegat, en un entorn absolutament innovador i de total desconcert. I la comunicació personal va deixar de ser possible físicament, la vam substituir per les trucades, les videoconferències, aplicacions de missatges de veu com WhatsApp i el correu electrònic, però això tingué unes conseqüències.

En aquest treball recollim les inquietuds i esperances sobre la comunicació interna i les seves implicacions a nivell de gestió de directius que en aquelles primeres setmanes intentaven seguir endavant, en la mesura del possible, amb els seus negocis.

\section{MARC TEÒRIC}

\subsection{Comunicació $i$ societat}

Cecilia Nicoli (2015) indica que «sovint repetim que el que distingeix els éssers humans d'altres éssers vius és la capacitat de comunicar-se a través del llenguatge i la seva vocació de viure en societat com a ésser gregari en cerca d'un benestar comú (últimament bastant discutible). Però descobrim que descansant en la idea que la comunicació és quelcom inherent a nosaltres, sovint ens oblidem de pensar en ella com una de les eines més importants per funcionar com a societat $i$, com a conseqüència, no li dediquem el temps i els recursos necessaris per organitzar-la».

\subsection{Comunicació interna}

La comunicació interna és una eina de gestió estratègica, i com a tal s'ha de planificar, no es pot deixar al natural funcionament de les converses entre persones. En aquest sentit, Cervera (2015) defensa que «la comunicació interna és el principal artífex de la transparència en l'organització $i$, per tant, no s'ha de considerar com un mer vehicle de transmissió d'informació, ni tan sols com un bon mètode de gestió a seguir de tant en tant. Cal veure-la com una funció inherent a qualsevol tasca i és necessari concretar-la i definir-la amb precisió». 
Per la seva part, Berceruelo (2011) indica que «en l'activitat d'una empresa, la comunicació interna respon a la necessitat específica de les empreses a motivar i integrar els seus empleats en un entorn empresarial que de vegades és canviant. Des d'aquest punt de vista, és una eina que permet transmetre els objectius a tota l'organització, difondre les seves polítiques i construir una identitat de l'empresa en un clima de confiança i de motivació».

Berceruelo (2011) afegeix que «la comunicació interna permet a l'organització mantenir la coordinació entre els seus diferents departaments afavorint així la interacció i l'assoliment dels objectius estratègics i l'eliminació de tensions i conflictes en les relacions interpersonals». Però no només la comunicació formal és important, segons Moret i Arcila (2011), «la comunicació informal compleix unes funcions específiques, des de ser un contrapès a l'estructura de poder fins a ser una alternativa de comunicació a la formalitzada per l'organització. Quan parlem de la cultura i la identitat en l'organització també parlem d'uns valors, creences, principis que formalment la gerència reconeix com els rectors de la seva acció corporativa, i, d'altra banda, sent conseqüents amb el nostre plantejament sobre la informalitat, els membres de l'organització també van narrant, recreant $\mathrm{i}$ interpretant el que succeeix a l'empresa».

\subsection{Comunicació interna i tecnologia}

Per Tessi (2012), «si bé les eines 2.0 estan en auge en la interacció amb els públics externs de les empreses, encara existeixen reticències a l'hora d'aplicar-les en la comunicació interna. Ja s'ha assumit que no es pot controlar el que els usuaris publiquen a internet, però no sembla tan senzill aplicar aquesta mateixa llibertat $o$ absència de control amb els públics interns. Moltes empreses tenen por de les crítiques, d'obrir la caixa de Pandora i que el seu blog o intranet es vegin envaïts de comentaris negatius. Tanmateix, aquesta és una manera excel-lent d'intentar portar els rumors de passadís a un àmbit en el qual l'empresa pot escoltar de forma activa i reaccionar donant resposta a les crítiques i necessitats dels empleats, transmetent missatges creïbles i generant transparència».

Per la seva part, Nicoli (2015) apunta que «els avenços tecnològics van començar a acompanyar aquest canvi de paradigma i la tecnologia va servir com a canal per impulsar el valor de la comunicació. Actualment, gairebé cap empresa passa per alt la importància de comptar amb un pla de comunicació interna, amb activitats que impulsin la conversa positiva entre empleats i caps i amb plataformes o eines tecnològiques que permetin una comunicació ubiqua, més fluida i més directa».

\section{Metodologia}

La metodologia utilitzada ha estat qualitativa, mitjançant la tècnica Delphi. Aquesta tècnica compta amb la participació de diversos experts els punts de vista dels quals poden i han de ser diferents, però tots ells aporten informació valuosa per entendre la situació objecte d'estudi. L'apropament a la informació es fa de manera iterativa. És una tècnica prospectiva, que permet preveure com serà el futur del tòpic que s'està investigant.

En l'estudi hi van participar set directius d'empreses grans (més de 250 treballadors), vuit directius d'empreses mitjanes i petites (menys de 250 treballadors) i cinc gestors d'entitats sense ànim de lucre 0 associacions.

Els participants es van repartir en tres grups (empreses grans, empreses mitjanes i petites i entitats sense ànim de lucre o associacions) i se'ls van oferir tres temes sobre els quals debatre de manera oberta: relacions dins de l'organització, relacions amb els clients 
i proveïdors i impacte social. A més, es va realitzar una enquesta en finalitzar el debat sobre cada un dels tres temes.

La recollida d'informació es va dur a terme entre el 16 d'abril i el 26 de maig de 2020, per tant, durant el període del primer confinament, tant a Espanya com a Colòmbia.

\section{ANÀLisi de RESUltats}

La importància de la comunicació interna es va posar de manifest en les intervencions sobre el primer dels temes del debat, el que se centrava en les relacions dins de l'organització. Les aportacions que els assistents van fer foren les següents:

(1) Lideratge i comunicació. Els directius concorden que per liderar els seus equips de treball el tracte proper i personal és important. Aquesta nova situació els obliga a ser més a prop dels seus equips per guiar-los davant dels canvis que es van presentant, i per a això és imprescindible millorar la comunicació, ja que tots els dies es prenen decisions que cal comunicar i nous rols (per la pandèmia) que cal recolzar.

(2) S'ha donat, i romandrà en el temps, l'increment en l'ús de les tecnologies per a la comunicació. Això suposa formar els empleats en l'ús d'aquestes tecnologies, ja que, si bé alguns ja estan familiaritzats amb la tecnologia i estan preparats per mantenir videoconferències de manera eficaç, també hi ha empleats que no es desenvolupen amb facilitat amb les noves tecnologies, i per a aquests un procés d'adaptació hauria estat important, tot i que impossible, tal com han succeït els esdeveniments.

(3) Guanya el vídeo. Dins de les tecnologies que ens permeten comunicar-nos a distància, com les trucades telefòniques, el correu electrònic o el WhatsApp, el vídeo és la preferida, ja que permet una major interacció.

(4) Pèrdua d'informació. Els assistents estan d'acord que la comunicació personal és molt més efectiva que les videoconferències, en què inevitablement es perd aquella lectura ràpida de les faccions i expressions dels nostres interlocutors, així com del seu llenguatge corporal. Aquesta pèrdua d'informació es tradueix en una percepció de les videoconferències com un mitjà molt més fred i impersonal.

(5) Increment de l'eficàcia. Sobretot, des del punt de vista de les grans empreses, es considera que les videoconferències afegeixen eficiència i focalització cap als objectius de les reunions, que s'agilitzen, duren menys temps que les reunions personals, i això ajuda que es prenguin decisions més ràpidament.

(6) Pèrdua de la comunicació informal. Amb les hores de treball en un mateix entorn laboral, es creen vincles, gràcies a converses informals, bromes o fins i tot sessions "d'esbroncada", que comporten, sens dubte, una pèrdua d'informació, però, sobretot, aporten una carència en la gestió de les emocions en l'organització.

(7) La comunicació s'humanitza. Tal com recullen les mateixes autores en un article publicat sobre la mateixa investigació: «Els experts de l'àrea de recursos humans consideren que la situació del confinament ha permès prendre consciència sobre aspectes relacionats amb l'ambient laboral. Entre ells, la necessitat d'escoltar més els treballadors i buscar maneres que els empleats se sentin més segurs amb el seu paper a l'empresa. A més, després de l'emergència sanitària serà necessari implementar 
capacitacions i seguiment sobre canvis en el comportament que ha portat la crisi de la COVID-19. Els participants de càrrecs de recursos humans manifesten una major preocupació pel treball a distància, ja que consideren que la seva tasca requereix relació personal. Directius de l'àrea comercial consideren que és important definir qui, quan i com s'implementaran les comunicacions. És possible que es requereixi una comunicació més freqüent pels constants canvis que s'han produït arran de la COVID-19».

\section{DisCUSSIÓ DE RESULTATS}

Amb aquesta investigació hem pogut constatar com, entre les inquietuds i aportacions dels assistents en relació amb la comunicació interna, han aparegut tots aquests temes que hem anat analitzant durant la revisió bibliogràfica. Així, per exemple, veiem com la funció de gestió estratègica que defineix Cervera (2015) o el punt de vista aportat per Berceruelo (2011) tenen el seu eco en totes aquestes aportacions en què es parla de lideratge i comunicació, així com en les aportacions que tracten l'increment de l'eficàcia en utilitzar les noves tecnologies.

També trobem concordança entre aquest estudi i la publicació de Cervera (2015), ja que aquest autor diu que cal definir els elements a transmetre amb precisió. En aquesta nova realitat això és més important per la impossibilitat de l'intercanvi personal, per això s'han de planejar millor les reunions i els missatges. Augmenta la importància de la paraula escrita i de tractar de transmetre sentiments per aquest mitjà, d'acompanyar l'empleat.

Si considerem les aportacions de Moret i Arcila (2011), que defensen que la comunicació informal compleix unes funcions específiques, veiem com els assistents troben a faltar aquesta comunicació informal, que és difícil de mantenir quan no es poden tenir entrevistes o converses personals. En aquest sentit, queda clar que la comunicació a través de videoconferències no permet mantenir aquesta comunicació informal, amb la conseqüent pèrdua d'informació, a la qual s'ha d'afegir la pèrdua en la relació entre el personal de l'empresa.

\section{Conclusions}

Sense cap mena de dubte, moltes coses han canviat a causa de la COVID-19, i la comunicació interna n'és una. S'ha vist clarament afectada pel canvi que suposa el teletreball, si bé és cert que les noves tecnologies aporten flexibilitat, rapidesa i són un pal-liatiu a la falta de comunicació en què cauríem o en què caiem en estar confinats; tanmateix, no són la solució ni un substitut eficaç a la comunicació personal.

La comunicació interna a les empreses ja fa molts anys que es considera un element de gestió que es planifica perquè flueixi de manera formal en aquells casos en què és necessari, però en què també es fomenta la comunicació informal, atès que aquesta última permet establir comunicacions molt riques en matisos de forma àgil i flexible. Aquesta comunicació informal es perd quan estem en confinament, ja que no podem establir aquella comunicació fluida natural que es produeix en els passadissos de les empreses, aquell intercanvi d'opinions que es dona en un moment determinat s'ha perdut totalment amb el confinament, i això és un problema, ja que genera una desafecció entre les persones que no tenen una relació tan propera i una incapacitat de traslladar tota la informació necessària. Així que la comunicació interna s'ha vist afectada en dues línies: d'una banda, hem perdut la connexió entre les persones, i, de l'altra, hem perdut, en part, capacitat de transmetre informació. 
Però no tot és negatiu, el confinament i l'ús de les noves tecnologies han tingut la seva part positiva. Una és que s'ha agilitzat la presa de decisions, s'han reduït els temps de les reunions i, a més, hem après a usar les noves tecnologies. Potser l'aportació més interessant sigui la d'apropar les persones, la d'humanitzar les comunicacions, però possiblement no sigui fruit de l'ús de les tecnologies, sinó fruit de la situació que estem vivint.

Finalment, podem concloure que tot apunta que en el futur la comunicació interna buscarà novament el contacte personal, però s'haurà acostumat a l'ús de les noves tecnologies. La comunicació interna de les empreses a partir d'ara combinarà de manera més efectiva les converses personals formals i informals amb les converses a través de videoconferència.

\section{LIMITACIONS}

La primera limitació que hem de destacar en aquest treball és que l'objectiu no era el d'indagar en com evoluciona la comunicació interna de les empreses, aquest ha estat un tema que ha aparegut de manera espontània entre els participants i que hem volgut recollir en aquest document. Per tant, no s'ha realitzat una cerca activa de com està funcionant la comunicació interna actualment o com funcionarà en el futur, sinó que és fruit de les aportacions espontànies.

Una altra de les limitacions és la dificultat de la participació per part dels assistents; l'estudi es va dur a terme durant els primers temps de la COVID-19, en ple confinament, i això significa que els directius que hi participaven tenien una situació molt complicada a les seves empreses, cosa que els dificultava una participació més activa en tot el procés d’investigació.

\section{FutURES LÍNIES D’INVESTIGACIÓ}

Indagar sobre què ha passat amb la comunicació interna després d'un any complet de COVID-19, en el qual hem intercalat períodes de confinament amb períodes d'una major obertura en què hem après a teletreballar i en què hem fet un ús intensiu de les noves tecnologies.

Potser sigui interessant realitzar un estudi l'objectiu del qual sigui conèixer com s'ha estructurat la comunicació interna a les empreses, tant des d'un punt de vista formal, és a dir, si hi ha hagut modificacions en l'ús de les tecnologies abans i després d'aquesta experiència, com en el tipus de continguts que es traslladen.

\section{REFERÈnCIES BibliogrÀFIQUES}

BERCERUElo, Benito (2011). «Comunicación interna en la empresa: claves y desafíos». Wolters Kluwer, editorial, núm. 1.

Cervera, Angel Luis (2015). Comunicación Total. Esic editorial.

Moret, Jorge; Arcila, Carlos (2011). «Comunicación interna e informal en las organizaciones». Temas de comunicación, núm. 22, pp. 7-23.

Nicoli, Cecilia (2015). «La comunicación interna y la tecnología o el abismo». Más poder local, núm. 24, pp. 34-36.

Tessi, Manuel (2012). Comunicación interna en la práctica: siete premisas para la comunicación en el trabajo. Ediciones Granica. 